\title{
PHÂN TÍCH Cơ CẤU DANH MỤC THUỐC SỬ DỤNG TẠI BỆNH VIỆN NộI TIẾT TRUNG ƯƠNG GIAI ĐOẠN 2019-2020
}

\author{
Nguyễn Thị Nhung ${ }^{1}$, Nguyễn Thị Thanh Hương ${ }^{2}$
}

\section{TÓM TẮT}

Đặt vấn đề: Cơ cấu các thuốc sử dụng tại cơ sở y tế phản ánh một số bất câp liên quan đến sử dụng thuốc giúp nhà quản lý có các giải pháp quản lý các hoạt động mua sắm và kê đơn thuốc ngày càng hợp lý hơn. Mục tiêu của nghiên cứu là mô tả cơ cấu thuốc sử dụng theo một số chỉ số và theo phương pháp $A B C$, VEN. Đối tượng và phương pháp: 411 khoản mục thuốc được sử dụng tại bệnh viện Nội Tiết TW giai đoạn 2019-2020 (12/7/2019-11/7/2020). Phương pháp nghiên cứu: mô tả cắt ngang. Kết quả: 411 khoản muc thuốc tương ứng 245.129 tỷ đồng. Nhóm thuốc Hormon và các thuốc tác động vào hệ nội tiết với 69 khoản mục (16.87\%) và 101.504 tỷ đồng (42.26\%). Thuốc tân dược sử dụng 409 khoản mục (99.51\%) với giá trị 240.146 tỷ đồng $(99.97 \%)$. Thuốc nhập khẩu sử dụng 280 khoản $(68.46 \%)$ với giá trị 215.132 tỷ đồng (89.58\%). Thuốc Biệt dược gốc chiếm $56.07 \%$ giá trị sử dụng. Cơ cấu các thuốc sử dụng theo phân hạng $A B C$ về giá trị sử dụng: hạng $A$ chiếm $79.78 \%$; hạng $B$ chiếm $15.15 \%$; hạng $C$ chiếm $5.07 \%$. Trong các thuốc hạng $A$ : nhóm hormone và các thuốc tác động vào hệ nội tiết chiếm $46.21 \%$ giá trị sử dụng. Bệnh viện không sử dụng các thuốc nhóm AN. Kết luận: Cơ cẫu thuốc sử dụng tại Bệnh viện Nội Tiết Trung Ương là tương đối hợp lý. Tuy nhiên, Bệnh viện cần có sự điều chỉnh giảm thuốc nhập khẩu và thuốc Biệt dược gốc cho phù hợp.

\section{SUMMARY \\ ANALYSIS OF DRUG CONSUMPTION IN NATIONAL HOSPITAL OF ENDOCRINOLGY IN 2019-2020}

Background and Objectives: Analysis of healthcare drug use can provide detailed information about the facility's inappropriate use of medications and assist healthcare providers in administering prescriptions. and buy medicine. medicine. The main objective of the study is to describe the distribution of drug use by the National Hospital of Endocrinolgy. Methods: This is a cross-sectional study covering 411 drug items distributed by the Department of Pharmacy in a hospital between 2019 and 2020 (July 12, 2019July 11,2020$)$. The study used $A B C$ and VEN methods to analyze data. Results: 411 drug items corresponding to 245,129 billion VND. The group of hormones and drugs affecting the endocrine system with 69 items $(16.87 \%)$ and VND 101,504 billion (42.26\%). Modern medicine uses 409 items (99.51\%)

${ }^{1}$ Bệnh viện Nôii Tiết TW

2Trường Đại hoc Dước Hà Nội

Chịu trách nhiệm chính: Nguyễn Thị Nhung

Email: nguyennhung268@yahoo.co.uk

Ngày nhận bài: 13.01.2021

Ngày phản biên khoa hoc: 15.3.2021

Ngày duyệt bài: 24.3.2021 with a value of VND 240,146 billion (99.97\%). Imported drugs used 280 items $(68.46 \%)$ with a value of VND 215,132 billion (89.58\%). Brand-name drug accounts for $56.07 \%$ of the value of use. The structure of drugs used according to $A B C$ classification in terms of use value: Grade A accounts for $79.78 \%$; Grade B accounts for $15.15 \%$; Grade C accounts for $5.07 \%$. In class $A$ drugs: hormone groups and drugs affecting the endocrine system account for $46.21 \%$ of the value of use. Hospitals do not use drugs of group AN. Conclusions: The structure used at the Central Endocrine Hospital is relatively reasonable. However, hospitals need to adjust imported and generic drugs accordingly.

Keywords: consumption drugs, ABC, VEN, National Hospital of Endocrinolgy, Vietnam

\section{I. ĐĂT VẤN ĐỀ}

Sử dụng thuốc không hợp lý đã và đang là vấn đề được quan tâm trên toàn câu với những hậu quả nghiêm trọng như làm gia tăng chi phí điêu trị, gia tăng tình trạng kháng thuốc và làm giảm chất lượng chăm sóc sức khỏe. Tại Bệnh viện, sự có mặt của Hội đồng thuốc và điều trị với nhiệm vụ tư vấn cho Giám đốc bệnh viện các vấn đề liên quan đến thuốc và điều trị bằng thuốc nhằm đảm bảo sử dụng thuốc hợp lý, an toàn, hiệu quả. Thông tư số 21 năm 2013 quy định chức năng, nhiệm vụ của Hội đồng thuốc và điều trị, trong đó có nhiệm vụ phân tích các vấn đề liên quan đến sử dụng thuốc ${ }^{[2]}$. Có một số phương pháp được sử dụng trong đánh giá sử dụng thuốc đã được khuyến cáo và áp dụng tại các cơ sở y tế như phương pháp phân tích ABC, VEN danh mục thuốc sử dụng ${ }^{[2][8]}$. Ma trận ABC/VEN cho thấy những thuốc cân quản lý chặt chẽ hơn đặc biệt là các thuốc hạng $A$, thuốc thuộc phân nhóm AN.

Bệnh viện Nội Tiết TW là Bệnh viện chuyên khoa đâu ngành trong lĩnh vực nội tiết và rối loạn chuyển hóa. Với sự phát triển không ngừng của Bệnh viện, hiện nay số bệnh nhân ngoại trú ở cả 2 cơ sở đã tăng lên trên 2000 người/ngày (tăng gấp 4 -5 lân so với trước đây); tổng số giường bệnh nội trú thực kê là 1104 giường (tăng gân gấp 2 lần so với năm 2012) [1],. Với đặc thù là Bệnh viện chuyên khoa trong lĩnh vực nội tiết và rối loạn chuyển hóa, mô hình Bệnh tật tại Bệnh viện Nội Tiết TW có tỷ lệ mắc các bệnh nội tiết, dinh dưỡng và chuyển hóa chiếm tỷ lệ cao nhất với $82.3 \%$. Hằng năm, Bệnh viện sứ dụng một lượng lớn các thuốc để phục vụ công 
tác khám, chữa bệnh tại bệnh viện. Bên cạnh đó, trong những năm gần đây, các thuốc điều trị bệnh lý nội tiết và rối loạn chuyển hóa được nghiên cứu, phát triển và đưa vào lưu hành trển thị trường ngày một nhiêu. Do vậy, việc tăng cường lựa chọn và sử dụng thuốc hợp lý, an toàn và hiệu quả là một trong những vấn đề rất được quan tâm và chú trọng. Để tìm ra những vấn đề chưa hợp lý trong cơ cấu thuốc sử dụng, làm cơ sở cho việc đề xuất các giải pháp tăng cường quản lý sử dụng thuốc hợp lý tại Bệnh viện trong những năm tiếp theo, chúng tôi tiến hành phân tích cơ cấu thuốc sử dụng tại Bệnh viện Nội Tiết TW giai đoạn 2019-2020.

\section{II. ĐỐI TƯỢNG VÀ PHƯƠNG PHÁP NGHIÊN CỨU}

2.1 Đối tượng nghiên cứu. Toàn bộ thuốc đã sử dụng trong giai đoạn 2019-2020 (từ $12 / 7 / 2019$ đến 11/7/2020 được tính theo thời gian gói thầu chính của bệnh viện) tại Bệnh viện Nội Tiết Trung Ương gồm 411 khoản mục thuốc.

2.2. Phương pháp nghiên cứu: Mô tả cắt ngang sử dụng số liệu hồi cứu

Xử lý số liệu: Số liệu được kết xuất ra file
Excel, làm sạch số liệu đảm bảo tính đầy đủ và chính xác của các số liệu sử dụng. Tiến hành phân loại các thuốc sử dụng (căn cứ vào tên hoạt chất đối với thuốc hóa dược; thành phần của thuốc đối với chế phẩm y học cổ truyền) theo phân loại VEN (V: Vital - Thuốc tối cần; E: Essential - Thuốc thiết yếu; $\mathrm{N}$ : Non- essential Thuốc không thiết yếu) dựa trên hướng dẫn của WHO[8], hướng dẫn của Bộ Y tế tại Thông tư số 21/2013 [2], đối chiếu với Danh mục thuốc thiết yếu năm 2018 do Bộ $Y$ tế ban hành ${ }^{[3]}$, tham khảo Danh mục thuốc thiết yếu của WHO năm $2017^{[8]}$. Sử dụng phần mềm Excel trong phân tích $A B C$ theo nguyên tắc hạng $A$ gồm các thuốc có tổng \% giá trị khoảng $80 \%$, hạng $\mathrm{B}$ khoảng $15 \%$ và hạng $C$ khoảng $5 \%$. Thông thường, sản phẩm hạng $\mathrm{A}$ chiếm $10-20 \%$ tổng sản phẩm; hạng $B$ chiếm $10-20 \%$ và $60-80 \%$ còn lại là hạng C. Sử dụng kỹ thuật phân tích ma trận ABC-VEN.

\section{KẾT QUẢ NGHIÊN CỨU}

3.1 Tỷ lệ thuốc hóa dược trong danh mục thuốc sử dụng

Bảng 3.1: Tỷ lệ khoản mục và giá trị thuốc hóa dược trong danh mục thuốc sử dụng

\begin{tabular}{|c|c|c|c|c|}
\hline Nội dung & Số khoản & \% khoản & Giá trị (1000 đ) & \% giá trị \\
\hline Thuốc hóa dược & 409 & 99,6 & 240.146 .638 & 97,96 \\
\hline Thuốc phóng xạ và hợp chất đánh dấu & 1 & 0,2 & 4.942 .164 & 2,02 \\
\hline Thuổc tự pha chế & 1 & 0,2 & 41.071 & 0,02 \\
\hline Tổng & $\mathbf{4 1 1}$ & $\mathbf{1 0 0 , 0}$ & $\mathbf{2 4 5 . 1 2 9 . 8 7 3}$ & $\mathbf{1 0 0 , 0}$ \\
\hline
\end{tabular}

Trong giai đoạn 2019-2020, bệnh viện Nội Tiết TW đã sử dụng hơn 245 tỷ đồng tiên thuốc của 411 khoản mục, trong đó thuốc hóa dược chiếm 99,96\% giá trị sử dụng.

\subsection{Cơ cấu thuốc hóa dược sử dụng theo nhóm tác dụng dược lý}

Bảng 3.2: Tỷ lệ khoản mục và giá trị thuốc sử dụng theo nhóm tác dụng dược lý

\begin{tabular}{|c|c|c|c|c|}
\hline \multirow[b]{2}{*}{ Nhóm TDDL } & \multicolumn{2}{|c|}{ Khoản mục } & \multicolumn{2}{|c|}{ Giá trị sứ dụng } \\
\hline & $\begin{array}{c}\text { Số } \\
\text { lướng }\end{array}$ & $\begin{array}{l}\text { Tỷ lệ } \\
(\%)\end{array}$ & $\begin{array}{c}\text { Giá trị } \\
\text { (1000 VNĐ) }\end{array}$ & $\begin{array}{l}\text { Tỷ lệ } \\
(\%)\end{array}$ \\
\hline Hormon và các thuốc tác động vào hệ nội tiết & 69 & 16,87 & 101.504 .486 & 42,27 \\
\hline Insulin và các thuốc hạ đường huyết & 50 & 12,22 & 97.264 .817 & 40,50 \\
\hline $\begin{array}{c}\text { Hormon tuyến giáp, cận giáp và các thuốc kháng } \\
\text { giáp trạng tổng hợp }\end{array}$ & 8 & 1,96 & 1.924 .629 & 0,81 \\
\hline Thuốc điều trị bệnh đái tháo nhạt & 2 & 0,49 & 1.699 .150 & 0,70 \\
\hline Hormon thượng thận và chất tống hợp thay thế & 7 & 1,71 & 521.821 & 0,22 \\
\hline Các chế phẩm androgen, estrogen và progesterone & 2 & 0,49 & 94.067 & 0,04 \\
\hline Thuốc tim mạch & 94 & 22,98 & 49.170 .485 & 20,48 \\
\hline Thuốc điêuu tri ký sinh trùng, chống nhiểm khuấn & 43 & 10,51 & 34.412 .674 & 14,33 \\
\hline $\begin{array}{c}\text { Thuốc chống rối loạn tâm thần và thuốc tác động } \\
\text { lên hệ thần kinh }\end{array}$ & 14 & 3,42 & 17.801 .882 & 7,41 \\
\hline $\begin{array}{l}\text { Dung dịch điều chỉnh nước, điện giải, cân bằng acid- } \\
\text { base và các dung dịch tiêm truyền khác }\end{array}$ & 35 & 8,56 & 6.943 .407 & 2,89 \\
\hline $\begin{array}{l}\text { Thuốc giảm đau, hạ sốt, chống viêm không steroid, } \\
\text { thuốc điều trị Gout và các bệnh xương khớp }\end{array}$ & 21 & 5,13 & 5.572 .824 & 2,32 \\
\hline Thuốc tác dụng đối với máu & 21 & 5,13 & 4.906 .795 & 2,04 \\
\hline Khoáng chất và vitamin & 10 & 2,44 & 4.629 .171 & 1,93 \\
\hline
\end{tabular}




\begin{tabular}{|c|c|c|c|c|}
\hline Thuốc gây mê, gây tê, thuốc giãn cơ, giải giãn cơ & 29 & 7,09 & 3.897 .009 & 1,62 \\
\hline Thuốc đường tiêu hóa & 32 & 7,82 & 3.803 .087 & 1,58 \\
\hline Thuốc chống co giật, chống động kinh & 4 & 0,98 & 2.832 .775 & 1,18 \\
\hline Nhóm thuốc còn lại (10 nhóm) & 37 & 9,05 & 4.672 .035 & 1,94 \\
\hline Tống số & $\mathbf{4 0 9}$ & $\mathbf{1 0 0}$ & $\mathbf{2 4 0 . 1 4 6 . 6 3 8}$ & $\mathbf{1 0 0}$ \\
\hline
\end{tabular}

Tổng chi phí thuốc hóa dược sử dung tai bệnh viện Nội Tiết TW giai đoạn 2019-2020 là hởn 240 tỷ đồng, bao gồm 409 khoản mục của 21 nhóm tác dụng dược lý. Ba nhóm thuốc có giá trị sử dụng cao nhất với tổng giá trị chiếm gần $80 \%$ gồm: thuốc Hormon và các thuốc tác động vào hệ nội tiết (chiếm 42,27\%); thuốc tim mạch (chiếm 20,47\%); thuốc điêu trị ký sinh trùng, chống nhiếm khuẩn (chiếm 14,32\%). Điều này cũng tương đối phù hợp với đặc điểm mô hình bệnh tật tại một bệnh viện chuyên khoa nội tiết và rối loạn chuyển hóa.
Trong nhóm thuốc Hormon và các thuốc tác động vào hệ nội tiết gồm 5 phân nhóm, Insulin và các thuốc hạ đường huyết có số khoản mục và giá trị sử dụng cao nhất với 69 khoản mục tương ứng 97,264 tỷ đông. Thuốc Hormon tuyển giáp, cận giáp và thuốc kháng giáp trạng tổng hợp với 8 khoản mục tương ứng 1,92 tỷ đồng. Thuốc điều trị bệnh đái tháo nhạt; thuốc Hormon thượng thận và chất tổng hợp thay thế; các chế phẩm androgen, estrogen và progesterone chiếm tỷ lệ nhỏ về khoản mục và giá trị sử dụng.

\subsection{Cơ cấu thuốc hóa dược sử dụng theo nguồn gốc và theo tên thuốc}

Bảng 3.3. Tỷ lệ khoản mục và giá trị thuốc hóa dược sử dụng theo nguồn gốc và theo tên thuốc

\begin{tabular}{|c|c|c|c|c|c|}
\hline$\pi$ & Nội dung & Số khoản & \% khoản & Giá trị (1000 đ) & \% giá trị \\
\hline \multicolumn{6}{|c|}{ Nguồn gốc Xuất xứ } \\
\hline 1 & Thuốc sản xuất trong nước & 129 & 31,5 & 25.014 .526 & 10,4 \\
\hline 2 & Thuốc nhập khấu & 280 & 68,5 & 215.132 .112 & 89,6 \\
\hline \multicolumn{6}{|c|}{ Thuốc Biệt dược gốc, thuốc Generic } \\
\hline 1 & Thuốc Biệt dược gốc & 128 & 31,3 & 134.639 .468 & 56,1 \\
\hline 2 & Thuốc Generic & 281 & 68,7 & 105.507 .170 & 43,9 \\
\hline & Tống & 409 & 100 & 240.146 .638 & 100 \\
\hline
\end{tabular}

Giai đoạn 2019-2020, Bênh viện Nội Tiết TW đã sử dung thuốc hóa dược nhập khấu với giá trị chiếm $89,6 \%$. Và tỷ lệ giá trị thuốc biệt dược gốc còn cao $(56,1 \%)$.

\subsection{Cơ cấu DMT sử dụng theo ma trận $A B C / V E N$}

Bảng 3.4: Cơ cấu danh mục thuốc sử dụng theo ma trận ABC/VEN

\begin{tabular}{|c|c|c|c|c|c|}
\hline \multirow{2}{*}{ Hạng } & \multirow{2}{*}{ Nhóm } & \multicolumn{2}{c|}{ Khoản mục } & \multicolumn{2}{c|}{ Giá trị sử dụng } \\
\cline { 2 - 6 } & & Số lượng & Tỳ lệ (\%) & Giá trị (1000 VNĐ) & Tỷ lệ (\%) \\
\hline \multirow{3}{*}{$\mathrm{A}$} & $\mathrm{V}$ & 3 & 0,73 & 4.405 .581 & 1,80 \\
\cline { 2 - 6 } & $\mathrm{E}$ & 64 & 15,57 & 191.168 .436 & 77,99 \\
\cline { 2 - 6 } & $\mathrm{N}$ & 0 & 0 & 0 & 0 \\
\hline \multirow{3}{*}{$\mathrm{B}$} & $\mathrm{V}$ & 6 & 1,46 & 2.543 .373 & 1,04 \\
\cline { 2 - 6 } & $\mathrm{E}$ & 57 & 13,87 & 31.758 .118 & 1,96 \\
\cline { 2 - 6 } & $\mathrm{N}$ & 6 & 1,46 & 2.837 .825 & 0,76 \\
\hline \multirow{3}{*}{$\mathrm{C}$} & $\mathrm{V}$ & 72 & 17,52 & 1.873 .758 & 3,87 \\
\cline { 2 - 6 } & $\mathrm{E}$ & 182 & 44,28 & 9.494 .169 & 0,43 \\
\cline { 2 - 6 } & $\mathrm{N}$ & 21 & 5,11 & 1.048 .609 & $\mathbf{1 0 0}$ \\
\hline \multicolumn{2}{|c|}{ Tống } & $\mathbf{4 1 1}$ & $\mathbf{1 0 0}$ & $\mathbf{2 4 5 . 1 2 9 . 8 7 3}$ & \\
\hline
\end{tabular}

Kết quả phân tích $\mathrm{ABC}$ cho thấy cơ cấu mua sắm tại bệnh viên là tương đối hợp lý với tỷ lê khoản mục thuốc hạng $A$ là 16,30\%; hạng $B$ là 16,79\% và hạng $C$ là 66,91\%. Bệnh viện không sử dụng thuốc AN. Trong số các thuốc nhóm $E$, phân nhóm AE có tỳ lệ giá trị sử dụng nhiều nhất $(77,99 \%)$.

3.5. Cơ cấu thuốc hạng $A$ theo nhóm tác dụng dược lý

Bảng 3.5. Cơ cấu thuốc hạng A theo nhóm tác dụng dược lý

\begin{tabular}{|c|c|c|c|c|c|}
\hline \multirow[b]{2}{*}{ TT } & \multirow[b]{2}{*}{ Nhóm tác dụng dược lý } & \multicolumn{2}{|c|}{ Khoản mục } & \multicolumn{2}{|c|}{ Giá trị sử dụng } \\
\hline & & $\begin{array}{c}\text { Số } \\
\text { lượng }\end{array}$ & $\begin{array}{l}\text { Tỷ lệ } \\
(\%)\end{array}$ & $\begin{array}{c}\text { Giá trị } \\
\text { (1000 VNĐ) }\end{array}$ & $\begin{array}{l}\text { Tỷ lệ } \\
(\%)\end{array}$ \\
\hline 1 & Hormon và các thuốc tác động vào hệ nội tiết & 26 & 38,81 & 90.384 .076 & 46,21 \\
\hline
\end{tabular}


TẠP CHÍ Y HỌC VIẸT NAM TẠP 501 - THÁNG 4 - SÓ 1 - 2021

\begin{tabular}{|c|c|c|c|c|c|}
\hline 2 & Thuốc tim mạch & 18 & 26,87 & 36.224 .609 & 18,52 \\
\hline 3 & Thuốc điêu trị ký sinh trùng, chống nhiếm khuấn & 8 & 11,94 & 28.209 .411 & 14,42 \\
\hline 4 & $\begin{array}{c}\text { Thuốc chống rối loạn tâm thần và thuốc tác } \\
\text { động lên hệ thần kinh }\end{array}$ & 4 & 5,97 & 16.864 .560 & 8,62 \\
\hline 5 & $\begin{array}{l}\text { Dung dịch điều chỉnh nước, điện giải, cân bằng } \\
\text { acid- base và các dung dịch tiêm truyền khác }\end{array}$ & 2 & 2,99 & 2.988.717 & 1,53 \\
\hline 6 & Khoáng chất và vitamin & 2 & 2,99 & 2.585 .612 & 1,32 \\
\hline 7 & Thuốc gây mê, gây tê, thuốc giãn cơ, giải giãn cơ & 2 & 2,99 & 2.328 .167 & 1,19 \\
\hline 8 & Thuốc chống co giật, chống động kinh & 1 & 1,49 & 2.467 .763 & 1,26 \\
\hline 9 & Thuốc điều trị bệnh da liều & 1 & 1,49 & 2.120 .000 & 1,08 \\
\hline 10 & $\begin{array}{l}\text { Thuốc giảm đau, hạ sốt, chống viêm không steroid, } \\
\text { thuốc điều trị Gout và các bệnh xương khớp }\end{array}$ & 1 & 1,49 & 1.520 & 2,24 \\
\hline 11 & Thuốc phóng xạ và hợp chất đánh dấu & 1 & 1,49 & 4.942 .164 & 2,53 \\
\hline 12 & Thuốc tác dụng đối với máu & 1 & 1,49 & 2.077.414 & 1,06 \\
\hline & Tổng & 67 & 100 & 195.574 .018 & 100 \\
\hline
\end{tabular}

Trong 67 thuốc hang A có 12 nhóm tác dung dược lý, 3 nhóm có giá trị sử dụng nhiều gồm: nhóm hormon và các thuốc tác động vào hê nội tiết $(38,81 \%$ khoản mục; $46,21 \%$ giá trị sử dụng); nhóm thuốc tim mạch $(26,87 \%$ khoản mục; $18,52 \%$ giá trị sử dụng); nhóm thuốc điều trị ký sinh trùng, chống nhiếm khuẩn $(14,42 \%$ khoản mục; $11,94 \%$ giá trị sử dụng).

\section{BÀN LUÂN}

Cơ cấu thuốc sử dụng tại Bệnh viện Nội Tiết TW giai đoạn 2019-2020 được xem xét trong 12 tháng theo thời gian gói thẩu (7/2019-7/2020), việc đánh giá sử dụng thuốc theo thời gian thuốc trúng thầu sẽ tránh được sai số về các thuốc cung ứng và sử dụng của thời gian gối thầu (sử dụng đồng thời thuốc của 2 gói thầu). Và như vậy việc đánh giá sẽ hợp lý hơn đối với cơ sở khám chữa bệnh trong việc khuyến nghị cơ sở về cung ứng sử dụng thuốc. Kết quả khảo sát cho thấy cơ cấu thuốc đã sử dụng tại bệnh viện cơ bản phù hợp với mô hình bệnh tật của một bệnh viện chuyên khoa nội tiết và rối loạn chuyển hóa thông qua tỷ lệ khoản mục và giá trị của một số nhóm thuốc được sử dụng chủ yếu như: nhóm Hormon và các thuốc tác động vào hệ nội tiết (16,87\% khoản mục; 44,27\% giá trị sử dụng); nhóm thuốc tim mạch (22,98\% khoản mục; $20,48 \%$ giá trị sử dụng).

Uuu tiên sử dung thuốc sản xuất trong nước được Bộ $Y$ tế quan tâm. Tuy nhiên một số bệnh viện tuyến trung ương do đặc thù mô hình bệnh tật nên tỷ lệ giá trị thuốc nhập khẩu được sử dụng còn cao hơn nhiều so với thuốc sản xuất trong nước. Cơ cấu danh mục thuốc sử dụng tại bệnh viện Nội Tiết Trung Ưởng cũng chỉ ra tỷ lệ vể giá trị sử dụng thuốc sản xuất trong nước chỉ chiếm $10,42 \%$. Tuy nhiên do thuốc sản xuất trong nước mới chỉ tập trung vào các nhóm thuốc thông thường với các dang bào chế đơn giản, các thuốc chuyên khoa như nhóm Hormon và các thuốc tác động vào hệ nội tiết thì hầu như ngành công nghiệp dược chưa sản xuất được. Là bênh viện chuyên khoa đầu ngành về nội tiết và rối loạn chuyển hóa, mô hình bệnh tật cho thây $82,3 \%$ là tỷ lệ mắc các bệnh nội tiết và rối loạn chuyển hóa mà ngành công nghiệp dược chưa đáp ứng được. Do vậy, bệnh viện vần phải sử dụng nhiều các thuốc nhập khẩu. Kết quả này tương tự với kết quả nghiên cứu của Bệnh viện Hữu nghị năm 2018 (13.14\%), bênh viện Bach Mai năm $2016(4.3 \%)$, bệnh viện Nhi TW năm

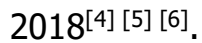

Để hạn chế tên biêt dược hoă̆c nhà sản xuất cu thể, Thông tư 21/2013/TT-BYT có quy đinh tiêu chí lựa chọn thuốc, trong đó ưu tiên lựa chọn thuốc generic hoặc thuốc mang tên chung quốc tế. Kết quả nghiên cứu về cơ cấu thuốc sử dụng tại bênh viện Nội Tiết trung ương cho thây tỷ lệ giá trị sử dụng thuốc biệt dược gốc chiếm $56,07 \%$. Kết quả này tương tự với kết quả của một số bệnh viện tuyến TW như Bệnh viện Bạch Mai năm 2016 (61,00\%); bênh viện Hữu Nghị năm $2018(57,51 \%)^{[4][5]}$. Sử dụng thuốc biệt dược gốc không chỉ chi phí tiền thuốc cao mà còn phân phối độc quyền nên viêc cung ứng đôi khi còn gặp khó khăn. Bệnh viện Nội Tiết TW nên cân nhắc, điều chỉnh, bổ sung các thuốc generic phù hợp vào danh mục thuốc bênh viên.

Kết quả phân tích ma trận $A B C / V E N$ cho thây bệnh viện nội tiết trung ương đã ưu tiên mua sắm các thuổc nhóm $\mathrm{V}, \mathrm{E}$ và cũng phân bổ phần lớn ngân sách vào 2 loại thuốc này ở cả 3 hạng A, B, C. Bênh viên không có tình trang sử dụng thuốc không cần thiết mà chi phí cao (thuốc trong phân nhóm AN). Mặc dù tỷ lệ giá trị thuốc nhóm $\mathrm{N}$ chỉ chiếm $1,59 \%$ giá trị sử dụng, tuy 
nhiên luôn là cần thiết việc rà soát hoat động phân loại thuốc theo VEN và giám sát chặt chẽ các thuổc nhóm $\mathrm{N}$ đã sử dụng tại bệnh viện.

\section{KẾT LUÂN}

Giai đoạn 2019-2020, Bênh viện Nội Tiết TW đã sử dụng nhiều nhất nhóm thuốc Hormon và các thuốc tác động vào hệ nội tiết (chiếm 42,27\% giá trị sử dụng); thuốc nhập khẩu chiếm giá trị sử dụng cao $(89,58 \%)$; thuốc biệt dược gốc có giá trị sử dụng chiếm $56,07 \%$. Phân tích $A B C / V E N$ cho thãy cơ cấu mua sắm thuốc tại bênh viện là hợp lý, không có nhóm thuốc Aì Các thuốc nhóm $\mathrm{N}$ sử dụng ít (chiếm 1,59\% giá trị sử dụng).

\section{TÀI LIÊU THAM KHẢO}

1. Bênh viện Nôi Tiết TW (2020), Kỷ yếu 50 năm thành lập bệnh viện,
2. Bộ Y tế (2013), Thông tư $21 / 2013 / T T-B Y T$ ngày 8/8/2013 Quy định về tổ chức và hoạt động của Hô̂i đồng Thuốc và điều trị trong bênh viên

3. Bổ Y tế (2018), Thông tư số $19 / 2018 / T$ T'-BYT ngày 30/8/2018 Ban hành Danh muc thuốc thiết yếu

4. Lê Thị Hằng (2020), Phân tích danh mục thuốc sử dung tai Bênh viên Hữu Nghi năm 2018; Luân văn thac sĩ dược hoc - Trường Đai học Dược Hà Nội

5. Lê Thi Tuyết Mai (2018), Phân tích danh muc thuốc sử dụng tại Bệnh viện Bạch Mai năm 2016; Luận văn thạc sĩ dược học - Trường Đại học Dược Hà Nôi

6. Nguyễn Thanh Uyên (2019), Phân tích danh muc thuốc sử dung tai Bênh viên Nhi TW năm 2018; Luận văn thạc sĩ dược học - Trường Đại học Dước Hà Nôi

7. Tổ chức Y tế Thế giới (2004), Hội đồng thuốc và điêuu tri - Cẩm nang hướng dân thực hành, trang 87-89,

8. WHO (2017); Model Lists of Essential Medicines (EML) $20^{\text {th }}$

\title{
NHẬN XÉT ĐĂC ĐIỂM LÂM SÀNG, CÂN LÂM SÀNG CỦA BỆNH NHÂN UNG THƯ DA DÀY ĐIỀU TRI BỔ TRƠ PHÁC ĐỒ CAPEOX TẠI BỆNH VIỆN QUÂN Y 103 VÀ BỆNH VIỆN BẠCH MAI
}

\author{
Hà Văn Trí1 ${ }^{1}$ Phạm Ngọc Điệp ${ }^{1}$ \\ Nghiêm Thị Minh Châu ${ }^{1}$, Phạm Cẩm Phương ${ }^{2}$
}

\section{TÓM TẮT}

Mục tiêu: Nhân xét đăc điểm lâm sàng, cân lâm sàng của các bệnh nhân ung thư da dày được điều trị bổ trợ bằng phác đồ CapeOx tai bệnh viện Quân Y 103 và bệnh viện Bạch Mai năm 2018-2020. Đối tương nghiên cứu: 40 bênh nhân ung thư da dày giai đoạn IB-III được điều trị bổ trợ bằng phác đồ CapeOx tai bênh viên 103 và bệnh viển Bach Mai năm 2018-2020. Các chỉ tiêu nghiên cứu gồm: tuổi, giới, tiền sử bênh lý da dày, triêu chứng lâm sàng, nồng đố CA72-4 trước phẫu thuật, thời gian chẩn đoán xác định bênh, vị trí tổn thương, thể mô bênh học, giai đoạn bệnh. Phương pháp: Nghiên cứu mô tả cắt ngang. Kết quả: Tuổi trung bình mắc bệnh là $57,4 \pm$ 10,4 ; tỷ lệ nam/nữ 3,44/1. Bênh hay gặp nhất trong độ tuổi từ 50 đến dưới 60 tuối. Triệu chứng lâm sàng đa dang và không đăc hiệu, trong đó triệu chứng thường gặp nhất là đau bụng thượng vị, chiếm $92,5 \%$, đây cũng là triêu chứng chủ yếu làm người bệnh đi khám; nhóm bệnh nhân không có tiền sử bểnh lý da dày chiểm tỷ ị̂̂ cao $45 \%$, nồng độ CA72-4 trước phẫu thuật tăng ở 45\% các trường hợp, giai

${ }^{1}$ Bệnh viện Quân Y 103

2 TT YHHN \& UB - Bênh viên Bach Mai

Chịu trách nhiệm chính: Hà Văn Trí

Email: dr.havantri1994@gmail.com

Ngày nhận bài: 11.01.2021

Ngày phản biên khoa hoc: 18.3.2021

Ngày duyệt bài: 29.3.2021 đoạn III có tỷ lệ tăng CA72-4 cao hơn so với giai đoạn IB-IIB với $p<0,05$. Vị trí tổn thương chủ yểu gặp ở vùng hang-môn vị $(60 \%)$ và bờ cong nhỏ của da dày $(32,5 \%)$. Phần lớn có thể mô học ung thư biểu mô tuyến kém biêtt hóa $(45 \%)$. Giai đoạn IIA và IIIA là giai đoạn phổ biến nhất, cùng chiếm $27,5 \%$. Số bệnh nhân giai đoan IB-IIA cao hơn số bệnh nhân giai đoạn IIIB-IIIC. Kết luân: Đặc điểm lâm sàng, cận lâm sàng bênh nhân ung thư dạ dày điều trị bố trợ bằng phác đồ CapeOx tai bệnh viện 103 và bệnh viện Bach Mai chưa khác biệt nhiều so với các nghiên cứu trước đây.

Tư khóa: Hóa trị bổ trơ ung thư da dày, phác đồ CapeOx, lâm sàng ung thư dạ dày.

\section{SUMMARY}

DESCRIBE CLINICAL AND SUBCLINICAL CHARACTERISTICS OF GASTRIC CANCER PATIENTS WHO RECEIVED ADJUVANT CHEMOTHERAPY USING CAPEOX REGIMEN AT MILITARY HOSPITAL 103 AND BACH MAI HOSPITAL

Objective: Describe clinical and subclinical characteristics of gastric cancer patients who received CapeOx adjuvant regimen at 103 military hospital and Bach Mai hospital from 2018-2020. Subjects: 40 gastric cancer patients who received CapeOx adjuvant regimen at the Military hospital 103 and Bach Mai hospital from 2018-2020. Research indexes include age, sex, history of gastric diseases, clinical symptoms, preoperative CA72-4 concentration, time of 